\title{
QUALIDADE SANITÁRIA E FISIOLÓGICA DE SEMENTES DE AROEIRA-PRETA (Lithraea molleoides) SUBMETIDAS A MÉTODOS DE SUPERAÇÃO DE DORMÊNCIA
}

\author{
HEALTH AND PHYSIOLOGICAL QUALITY OF AROEIRA-PRETA (Lithraea molleoides) \\ SEEDS EXPOSED TO METHODS OF OVERCOMING DORMANCY
}

\author{
Graziela Piveta $^{1}$ Marlove de Fátima Brião Muniz ${ }^{2}$ Lia Rejane Silveira Reiniger ${ }^{3}$ \\ Cláudia Braga Dutra ${ }^{4}$ Cleidionara Pacheco ${ }^{5}$
}

\begin{abstract}
RESUMO
O presente estudo teve como objetivo avaliar a qualidade fisiológica e sanitária de sementes de Lithraea molleoides (Vell.) Engl. comparando diferentes métodos de superação da dormência. Os métodos de superação da dormência utilizados foram: escarificação ácida por 10, 15, 20 e 25 minutos; imersão em água quente, com temperatura de 70,80 e $90^{\circ} \mathbf{C}$, até resfriar por 24 horas, imersão em ácido giberélico $\left(\mathrm{GA}_{3}\right)$ na concentração de 250 e $500 \mathrm{mg} . \mathrm{L}^{-1}$, por 24 e 48 horas; e imersão em nitrato de potássio $\left(\mathrm{KNO}_{3}\right)$ por 24 e 48 horas. Foram realizadas avaliações de sanidade, germinação e comprimento médio de plântulas. $\mathrm{O}$ delineamento experimental foi inteiramente casualizado, com quatro repetições de 25 sementes por tratamento. Os dados em percentagem foram transformados segundo arco sen $\sqrt{ } \mathrm{x} / 100$ e submetidos à análise de variância. A comparação das médias foi realizada através do teste de Tukey a $5 \%$ de significância. Foi realizada análise de correlação simples entre sementes mortas do teste de germinação e os diferentes fungos identificados no teste de sanidade. No teste de sanidade, foram identificados com maior incidência os fungos Rhizoctonia spp., Penicillium spp., Aspergillus spp., Alternaria spp., Chaetomium spp., Epicoccum spp. De uma maneira geral, a utilização da água quente controlou a incidência dos diferentes fungos e a utilização do ácido giberélico proporcionou um aumento da incidência dos diferentes patógenos. A maior porcentagem de germinação foi observada quando se utilizou escarificação ácida por 20 minutos, imersão em água quente a $70^{\circ} \mathrm{C}, \mathrm{GA}_{3}\left(250 \mathrm{mg} \mathrm{L}^{-1}\right.$ por 48 horas $)$ e $\mathrm{KNO}_{3}$ por 48 horas.
\end{abstract}

Palavras-chave: espécie florestal; germinação; fungos.

\section{ABSTRACT}

This study aimed to evaluate the physiological and sanitary quality of seeds Lithraea molleoides (Vell.) Engl. comparing different methods to overcome dormancy. Methods of overcoming dormancy were used: acid scarification for $10,15,20$ and 25 minutes soaking in hot water with temperatures of 70,80 and $90^{\circ} \mathrm{C}$, for 24 hours until cool, soaking in gibberellic acid $\left(\mathrm{GA}_{3}\right)$ in the concentration 250 and $500 \mathrm{mg} \cdot \mathrm{L}^{-1}$ for 24 and 48 hours, and immersion in potassium nitrate $\left(\mathrm{KNO}_{3}\right)$ for 24 and 48 hours. We evaluated health, germination and seedling length of the experimental design was completely randomized design with four replications of 25 seeds per treatment. The percentage data were transformed into the second $\operatorname{arc} \sin \sqrt{ } \mathrm{x} / 100$ and subjected

1 Engenheira Florestal, Msc., Doutoranda do Programa de Pós-Graduação em Engenharia Florestal, Centro de Ciências Rurais, Universidade Federal de Santa Maria, Av. Roraima, 1000, CEP 97105-900, Santa Maria (RS), Brasil.grazipiveta@yahoo.com.br

2 Engenheira Agrônoma, Dr $^{\text {a }}$, Professora Adjunta do Departamento de Defesa Fitossanitária, Centro de Ciências Rurais, Universidade Federal de Santa Maria, Av. Roraima, 1000, CEP 97105-900, Santa Maria (RS), Brasil. marlovemuniz@yahoo.com.br

3 Engenheira Agrônoma, Dr ${ }^{\mathrm{a}}$., Professora Adjunta do Departamento de Fitotecnia, Centro de Ciências Rurais, Universidade Federal de Santa Maria, Av. Roraima, 1000, CEP 97105-900, Santa Maria (RS), Brasil. liarejanesilveirareiniger@yahoo.com.br

4 Engenheira Agrônoma, Msc.cleidi_pacheco@hotmail.com

5 Acadêmica do Curso de Agronomia, Centro de Ciências Rurais, Universidade Federal de Santa Maria, Av. Roraima, 1000, CEP 97105-900, Santa Maria (RS), Brasil. c.bragadutra@yahoo.com.br

Recebido para publicação em 2/07/2011 e aceito em 14/12/2012 
to analysis of variance. Comparison of means was performed using the Tukey test at $5 \%$ significance level. Analysis was a simple correlation between the test of dead seeds test and the different fungi in identified sanity. In the health test, the fungi which had the highest incidence were Rhizoctonia spp., Penicillium spp., Aspergillus spp., Alternaria spp. Chaetomium spp. Epicoccum spp. In general, the use of hot water controlled the incidence of different fungi and the use of gibberellic acid resulted in an increase in the incidence of different pathogens. The highest percentage of germination was observed when using acid scarification for 20 minutes, soaking in hot water at $70^{\circ} \mathrm{C}, \mathrm{GA}_{3}\left(250 \mathrm{mg} \cdot \mathrm{L}^{-1}\right.$ for 48 hours $)$ and $\mathrm{KNO}_{3}$ for 48 hours.

Keywords: forest species, germination, fungi.

\section{INTRODUÇÃO}

Pertencente à família Anacardiaceae, Lithraea molleoides (Vell.) Engl. possui ocorrência natural de Minas Gerais até o Rio Grande do Sul (CARVALHO, 2006). Conhecida popularmente como aroeira-preta é uma espécie produtora de carvão e de lenha de grande poder calorífico. Sua madeira é útil para postes, construção civil, marcenaria, dormentes e mourões. A casca é rica em tanino, o que a torna resistente à putrefação, além de fornecer material tintorial. As folhas de aroeira-preta são aromáticas e medicinais, no entanto, é considerada extremamente cáustica, em função de causar severas reações alérgicas a pessoas pré-dispostas (CARVALHO, 2006).

Em muitas espécies florestais é comum encontrar sementes que, embora permanecendo viável por longos períodos no banco de sementes do solo, a germinação é lenta e irregular, mesmo quando expostas a condições ambientais favoráveis (MURDOCH e ELLIS, 2000). Esse fenômeno é denominado dormência e consiste em estratégia natural de sobrevivência da semente no solo, após maturação e dispersão, para garantir a perpetuação da espécie (PIÑA-RODRIGUES e AGUIAR, 1993). Neste caso, o conhecimento de suas causas é de importância prática, visto que permite a aplicação de tratamentos apropriados para se obter melhor germinação (MELO et al., 1998).

No laboratório, a utilização de métodos para a superação da dormência pode permitir uma germinação mais regular, rápida e completa das amostras de sementes de uma espécie (BRASIL, 2009). A escolha do método a ser aplicado depende do tipo de dormência, a qual pode ser exógena, quando relacionada com a impermeabilidade do tegumento ou do pericarpo à água; endógena que ocorre devido ao embrião imaturo ou à presença de mecanismos de inibição fisiológica e a combinada, que se dá com a combinação dos dois tipos de dormência citadas, ou seja, apresenta a dormência endógena e a exógena (CARVALHO, 2003).

Outro problema encontrado no processo de germinação em sementes florestais é a qualidade sanitária, o qual pode causar anormalidade e lesão na plântula, bem como a deterioração de semente. Sementes infectadas, comumente exibem redução na germinação, na emergência de plântulas e no vigor, o que leva a uma baixa população de plantas no campo. As plântulas podem ser mortas após a emergência ou terem o seu desenvolvimento reduzido. Além disso, as sementes infectadas ou infestadas por fungos constituem fonte de inóculo primário para as doenças, em condições de campo (PINTO, 1999). Para Menten (1991), a interferência dos patógenos associados às sementes pode promover a redução da população de plantas, a debilitação das mesmas e o desenvolvimento de epidemias.

Pouco se sabe sobre a germinação das sementes de Lithraea molleoides sob condições naturais e/ou controladas. Portanto, objetivou-se avaliar a qualidade sanitária e fisiológica das sementes de aroeira-preta e indicar o método que possa acelerar o processo de germinação.

\section{MATERIAL E MÉTODOS}

O trabalho foi conduzido no Laboratório de Pesquisa em Fitopatologia do Departamento de Defesa Fitossanitária da Universidade Federal de Santa Maria, Rio Grande do Sul (RS). As sementes utilizadas foram procedentes da Fundação Estadual de Pesquisa em Agropecuária - FLORESTAS (FEPAGRO-FLORESTA), e foram colhidas em 2007, na região de Boca-do-Monte, em Santa Maria - RS.

As sementes foram tratadas por meio de imersão em ácido sulfúrico $\left(\mathrm{H}_{2} \mathrm{SO}_{4}\right)$ a $90 \%$, por 10 , 15, 20 e 25 minutos; imersão em ácido giberélico, onde as sementes foram escarificadas em ácido sulfúrico $\left(\mathrm{H}_{2} \mathrm{SO}_{4}\right)$ a $90 \%$, por 15 minutos e, logo após, imersas em solução de ácido giberélico nas 
concentrações de 250 e $500 \mathrm{mg} . \mathrm{L}^{-1}$ por um período de 24 e 48 horas com a temperatura de $25^{\circ} \mathrm{C}$; imersão em água fervente, as sementes foram imersas em água aquecida até as temperaturas de 70, 80 e $90^{\circ} \mathrm{C}$, e colocadas para resfriar por 24 horas, em temperatura de $25^{\circ} \mathrm{C}$; imersão em nitrato de potássio $\left(\mathrm{KNO}_{3}\right)$ : as sementes foram escarificadas em ácido sulfúrico $\left(\mathrm{H}_{2} \mathrm{SO}_{4}\right)$ a $90 \%$, por 15 minutos e logo após, imersas na solução de nitrato de potássio na concentração de $0,2 \%$, por 24 e 48 horas com temperatura de $25^{\circ} \mathrm{C}$ e Testemunha, (sementes sem tratamento), totalizando 14 tratamentos.

Logo em seguida, foi conduzido o teste de geminação, composto de quatro repetições de 25 sementes, em substrato de rolo de papel, por que foram utilizadas 3 folhas de papel tipo germitest (papel-filtro), umedecidas com água destilada, equivalente a 2,5 vezes o peso do papel seco, conforme Brasil (2009). As sementes foram mantidas sob fotoperíodo de 12 horas de luz direta e temperatura constante de $25^{\circ} \mathrm{C}$. As avaliações foram realizadas semanalmente por um período de 30 dias. Foram avaliadas as plântulas normais (bem desenvolvidas e morfologicamente perfeitas, sem rachaduras ou lesões) e as sementes mortas.

A avaliação da qualidade sanitária foi realizada por meio do método "blotter-test", onde amostras de 100 sementes, divididas em quatro subamostras, foram colocadas em caixas plásticas tipo "gerbox", sobre três folhas de papel-filtro esterilizadas e umedecidas com água destilada e esterilizada. Logo após, foram incubadas em estufa, a temperatura de $25^{\circ} \mathrm{C}$, em fotoperíodo de 12 horas, durante sete dias. Logo após, foram avaliados os microrganismos presentes nas sementes, com auxílio de microscópios esterescópico e ótico. A identificação dos fungos foi realizada conforme descrição de Barnett e Hunter (1999).

O delineamento experimental foi inteiramente casualizado, com quatro repetições de 25 sementes por tratamento. Os dados em percentagem foram transformados em arco $\operatorname{sen} \sqrt{x} / 100$ e submetidos à análise de variância e a comparação das médias dos tratamentos através do teste de Tukey a $5 \%$ de significância. Foi realizada análise de correlação simples entre sementes mortas (teste de germinação) e os diferentes fungos (teste de sanidade). Os dados foram analisados pelo pacote estatístico Sistema de Análise Estatística para Microcomputador - SANEST (ZONTA e MACHADO, 1984).

\section{RESULTADOS E DISCUSSÃO}

Verificou-se que a escarificação ácida por 25 minutos prejudicou o processo de germinação das sementes (Tabela 1). Supõe-se que o aumento do tempo de exposição das sementes ao ácido sulfúrico pode danificar os tecidos internos da semente causando a morte do embrião, inibindo assim a germinação. Além disso, os tegumentos permaneceram presos aos cotilédones das plântulas.

$\mathrm{O}$ desprendimento dos cotilédones é um importante fator no desenvolvimento de plântulas normais. Cotilédones presos (temporária ou permanentemente) dentro dos tegumentos tornamse sujeitos a vários tipos de danos (VAN DER BURG et al., 1994). Segundo Copeland (1976), fatores diversos interferem na formação do tegumento durante o desenvolvimento da semente, propiciando variações quanto ao tempo de imersão em ácido sulfúrico.

A utilização da água quente a $70^{\circ} \mathrm{C}$ foi suficiente pra tornar o tegumento permeável permitindo a imediata embebição e o início do processo germinativo, porém, ao mesmo tempo, pode ter causado a morte dos tecidos embrionários das sementes reduzindo a porcentagem de germinação. Já para a porcentagem de sementes mortas, ocorreu um aumento à medida que se aumentou a temperatura da água. Para as espécies Stryphnodendron pulcherrimum (VARELA et al., 1991); Copaifera langsdorfii, Enterolobium contorsiliquum e Mimosa caesalpiniaefolia (MARTINS et al., 1992), a água fervente danificou o embrião para as espécies em estudo causando redução na porcentagem de germinação.

A germinação aumentou de $12 \%$ para $36 \%$ com a imersão em ácido giberélico $\left(\mathrm{GA}_{3}\right)$ na concentração de $250 \mathrm{mg} . \mathrm{L}^{-1}$ por 48 horas (Tabela 1). Verificou-se que, aumentando o tempo de imersão das sementes, aumentou o percentual de sementes germinadas quando se utilizou uma baixa concentração $\left(250 \mathrm{mg} \cdot \mathrm{L}^{-1}\right)$ de $\mathrm{GA}_{3}$. Quando se utilizou alta concentração (500 mg. $\left.\mathrm{L}^{-1}\right)$ constatou-se o inverso, ou seja, quanto menor o tempo de imersão maior foi o percentual da germinação. Portanto, pode ser utilizada uma baixa concentração de $\mathrm{GA}_{3}$ associado a um maior tempo de exposição das sementes ao $\mathrm{GA}_{3}$.

As giberelinas possuem efeito estimulatório no processo germinativo, atuando na ativação do crescimento vegetativo do embrião, mobilização das reservas do endosperma e no enfraquecimento 
da camada de endosperma que circunda o embrião, favorecendo assim seu crescimento (TAIZ e ZEIGER, 2009).

Stenzel et al. (2003), trabalhando com superação de dormência de sementes de Annona cherimola e Annona squamosa, concluíram que o uso do ácido giberélico a 50 e 100 ppm proporcionou porcentagem de germinação e índice de velocidade de germinação significativamente superiores às sementes não tratadas, independente do material genético.

Já Lucena et al. (2004), estudando a germinação de sementes de mamona (cultivar BRS 149 Nordestina), observaram que concentrações de ácido giberélico, variando entre zero a $800 \mathrm{ppm}$, não influenciaram no percentual de emergência nem no tempo para germinação de $50 \%$.

Lula et al. (2000), em estudos com sementes de Paspalum paniculatum, não obtiveram resultados satisfatórios quando utilizaram ácido giberélico, devido ao baixo percentual de germinação apresentado. Scalon et al. (2005) observaram que os tratamentos com giberelina não proporcionaram aumento na emergência das sementes de Enterolobium contortisiliquum. Porém, no estudo realizado com sementes de Smilax japecanga, foi observado que a utilização de ácido giberélico superou a dormência da espécie (SANTOS et al., 2004). Em outros estudos realizados, Marcos Filho et al. (1987) também confirmam a eficiência da aplicação de giberelina (GA3) para a superação da dormência em sementes de Helianthus annus, divulgando esse tratamento como o mais eficiente para essa espécie, assim como, em trabalho realizado por Laura et al. (1994) com Muntingia calabura que respondeu de forma altamente favorável a regulador de crescimento.

$\mathrm{O}$ efeito do $\mathrm{KNO}_{3}$ na superação da dormência tem sido investigado há muitos anos por vários autores (GARBER et al. 1974; FRANK e NABINGER, 1996; EIRA, 1983; GAZZIERO et al., 1991), os quais afirmam ser o nitrato de potássio um agente eficiente na promoção da germinação de muitas sementes dormentes.

$\mathrm{Na}$ Tabela 1 observa-se que não ocorreu diferença estatística para ambos os tempos de imersão em nitrato de potássio $\left(\mathrm{KNO}_{3}\right)$. Assim, a utilização de $\mathrm{KNO}_{3}$ proporcionou aumento na porcentagem de sementes germinadas de $12 \%$ para $20 \%$ no tempo de imersão por 24 horas e no tempo de 48 horas para $29 \%$ (Tabela 1). Portanto, o aumento de tempo de imersão em $\mathrm{KNO}_{3}$ incrementou a germinação de aroeira-preta.

Apesar da imersão das sementes em $\mathrm{KNO}_{3}$, para fins de superação da dormência, ter uso consagrado em laboratórios, o seu modo de ação ainda é bastante discutido. Alguns pesquisadores, como Frank e Nabinger (1996), aconselham o uso de $\mathrm{KNO}_{3}$ em sementes que possuem o tegumento impermeável a gases. Acredita-se que o $\mathrm{KNO}_{3}$, entrando em contato com substâncias existentes no pericarpo, amolece esse envoltório, facilitando as trocas gasosas.

A variável comprimento de plântulas, utilizada para avaliar o vigor de sementes, pode ser realizada em laboratório, sob condições controladas, ou em condições de campo (NAKAGAWA, 1999). $\mathrm{O}$ autor relata que a uniformidade é importante componente dentro do conceito atual de vigor de sementes. Observou-se neste estudo que os diferentes métodos de superação da dormência não prejudicaram o vigor das sementes, visto que não diferiram estatisticamente (Tabela 1). Segundo Nakagawa (1999) a determinação do comprimento médio das plântulas normais, ou de partes destas, é realizada tendo em vista que as amostras que apresentam os maiores valores médios são as mais vigorosas.

A qualidade sanitária das sementes também pode influenciar na germinação e no vigor das sementes, portanto, o teste de sanidade é imprescindível para verificar a qualidade das sementes.

No teste de sanidade (Tabela 2) verificouse a presença de Rhizoctonia spp., Penicillium spp., Aspergillus spp., Alternaria spp., Chaetomium spp., Epicoccum spp. e outros que ocorreram em menores incidências, tais como Rhizopus spp., Phoma spp., Cladosporium spp., Fusarium spp., Trichoderma spp. e Mucor spp.

Em estudo da qualidade sanitária de sementes de espécies da mesma família como Myracrodruon urundeuva (aroeira-verdadeira), encontraram Fusarium spp., Trichoderma spp., Aspergillus spp., Penicillium spp. e Phoma spp. presentes nas sementes (NOBRE et al., 2007). Muniz et al. (2003) observaram a presença de Alternaria spp., Monochaetia spp., Aspergillus spp., Fusarium spp., Cladosporium spp. e Penicillium spp. associados às sementes de Schinus terebinthifolius (aroeira-vermelha).

Neste trabalho, não ocorreu diferença estatística para Penicillium spp., Aspergillus spp. e Alternaria spp. quando se utilizou escarificação 
TABELA 1: Percentagem de sementes germinadas, mortas e comprimento médio de sementes de Lithraea molleoides submetidas a diferentes métodos de superação de dormência.

TABLE 1: Percentage of germinated seeds, and average length of dead seeds Lithraea molleoides submitted to different methods of scarification.

\begin{tabular}{|c|c|c|c|}
\hline Tratamento & Germinadas $(\%)$ & Sementes mortas $(\%)$ & Comprimento $(\mathrm{cm})$ \\
\hline \multicolumn{4}{|c|}{ Escarificação ácida } \\
\hline Testemunha & $12 \mathrm{~B}$ & $88 \mathrm{~A}$ & $4,0 \mathrm{~A}$ \\
\hline Escarificação ácida por 10 min. & $17 \mathrm{~B}$ & $83 \mathrm{~A}$ & $5,0 \mathrm{~A}$ \\
\hline Escarificação ácida por 15 min. & $17 \mathrm{~B}$ & $83 \mathrm{~A}$ & $4,2 \mathrm{~A}$ \\
\hline Escarificação ácida por 20 min. & $45 \mathrm{~A}$ & $55 \mathrm{~B}$ & $4,5 \mathrm{~A}$ \\
\hline Escarificação ácida por $25 \mathrm{~min}$. & $22 \mathrm{~B}$ & $78 \mathrm{~A}$ & $4,25 \mathrm{~A}$ \\
\hline $\mathrm{CV}(\%)$ & 2,93 & 1,99 & 22,34 \\
\hline \multicolumn{4}{|l|}{ Água quente } \\
\hline Testemunha & $12 \mathrm{C}$ & $88 \mathrm{~A}$ & $4,0 \mathrm{~A}$ \\
\hline Água quente a $70^{\circ} \mathrm{C}$ & $43 \mathrm{~A}$ & $51 \mathrm{C}$ & $3,5 \mathrm{~A}$ \\
\hline Água quente a $80^{\circ} \mathrm{C}$ & $34 \mathrm{AB}$ & $66 \mathrm{~B}$ & $3,5 \mathrm{~A}$ \\
\hline Água quente a $90^{\circ} \mathrm{C}$ & $28 \mathrm{~B}$ & $71 \mathrm{~B}$ & $3,7 \mathrm{~A}$ \\
\hline CV $(\%)$ & 1,94 & 1,89 & 20,34 \\
\hline \multicolumn{4}{|c|}{ Imersão em ácido giberélico } \\
\hline Testemunha & $12 \mathrm{CD}$ & $88 \mathrm{~A}$ & $4,0 \mathrm{~A}$ \\
\hline Imersão em $\mathrm{GA}_{3} 250$ por $24 \mathrm{~h}$ & $4,0 \mathrm{D}$ & $70 \mathrm{~A}$ & $4,25 \mathrm{~A}$ \\
\hline Imersão em $\mathrm{GA}_{3} 250$ por $48 \mathrm{~h}$ & $36 \mathrm{~A}$ & $80 \mathrm{~A}$ & $4,75 \mathrm{~A}$ \\
\hline Imersão em $\mathrm{GA}_{3} 500$ por $24 \mathrm{~h}$ & $31 \mathrm{AB}$ & $68 \mathrm{~A}$ & $4,25 \mathrm{~A}$ \\
\hline Imersão em $\mathrm{GA}_{3} 500$ por $48 \mathrm{~h}$ & $20 \mathrm{BC}$ & $80 \mathrm{~A}$ & $2,75 \mathrm{~A}$ \\
\hline CV $(\%)$ & 2,60 & 7,07 & 22,92 \\
\hline \multicolumn{4}{|c|}{ Imersão em $\mathrm{KNO}_{3}$} \\
\hline Testemunha & $12 \mathrm{~B}$ & $88 \mathrm{~A}$ & $4,0 \mathrm{~A}$ \\
\hline Imersão em $\mathrm{KNO}_{3}$ por $24 \mathrm{~h}$ & $20 \mathrm{AB}$ & $78 \mathrm{AB}$ & $5,0 \mathrm{~A}$ \\
\hline Imersão em $\mathrm{KNO}_{3}$ por $48 \mathrm{~h}$ & $29 \mathrm{~A}$ & $71 \mathrm{~B}$ & $4,25 \mathrm{~A}$ \\
\hline $\mathrm{CV}(\%)$ & 2,67 & 1,76 & 22,32 \\
\hline
\end{tabular}

Médias seguidas pela mesma letra na coluna não diferem estatisticamente entre si pelo teste Tukey ao nível de 5\% de probabilidade.

ácida. Verificou-se que a porcentagem de Rhizoctonia spp. e os fungos classificados como "outros" foram reduzidos quando se utilizou os diferentes tempos de imersão em ácido sulfúrico. De uma maneira geral, a utilização dos diferentes tempos de imersão em ácido sulfúrico reduziu o percentual dos diferentes fungos identificados no teste de sanidade. Assim sendo, a utilização do ácido sulfúrico contribui para o aumento da porcentagem de germinação (Tabela 1) e também para o controle dos diferentes fungos (Tabela 2).

Não ocorreu diferença estatística quando se avaliou a incidência de Penicillium spp. e Chaetomium spp. com o método água quente. Porém, ocorreu um aumento na porcentagem nos fungos classificados como "outros" e
Epicoccum spp. quando a temperatura da água utilizada foi de $70^{\circ} \mathrm{C}$. Portanto, a temperatura de $70^{\circ} \mathrm{C}$ contribui para o aumento da porcentagem de germinação, assim como, para o aumento da incidência de fungos. Provavelmente, a utilização da água quente auxilia na liberação de substâncias das sementes como compostos fenólicos entre outros, o que pode alterar o $\mathrm{pH}$ da superfície das sementes, favorecendo o desenvolvimento dos fungos.

$\mathrm{O}$ método de imersão em ácido giberélico contribuiu para o aumento da porcentagem de Penicillium spp., que, segundo Christensen (1973), Penicillium spp. é considerado fungo de armazenamento e a sua incidência pode aumentar no período pós-colheita. Segundo Oliveira et al. (1997), estes fungos quando associados às sementes 
TABELA 2: Incidência de fungos associados às sementes de Lithraea molleoides, submetidas aos diferentes métodos de superação de dormência.

TABLE 2: Incidence of seed fungi of Lithraea molleoides, subjected to different methods of scarification.

\begin{tabular}{|c|c|c|c|c|c|}
\hline \multicolumn{6}{|c|}{ Escarificação ácida } \\
\hline & Rhizoctonia spp. & Penicillium spp. & Aspergillus spp. & Alternaria spp. & Outros \\
\hline Testemunha & $83,0 \mathrm{~A}$ & $8,81 \mathrm{~A}$ & $13,0 \mathrm{~A}$ & $2,0 \mathrm{~A}$ & $33,0 \mathrm{~A}$ \\
\hline Escarif. ácida por $10 \mathrm{~min}$. & $0,0 \mathrm{~B}$ & $0,0 \mathrm{~A}$ & $3,0 \mathrm{~A}$ & $0,0 \mathrm{~A}$ & $19,0 \mathrm{AB}$ \\
\hline Escarif. ácida por $15 \mathrm{~min}$. & $2,0 \mathrm{~B}$ & $2,0 \mathrm{~A}$ & $1,0 \mathrm{~A}$ & $4,0 \mathrm{~A}$ & $3,0 \mathrm{~B}$ \\
\hline Escarif. ácida por $20 \mathrm{~min}$. & $10,0 \mathrm{~B}$ & $3,0 \mathrm{~A}$ & $15,0 \mathrm{~A}$ & $8,0 \mathrm{~A}$ & $5,0 \mathrm{~B}$ \\
\hline Escarif. ácida por $25 \mathrm{~min}$. & $0,0 \mathrm{~B}$ & $0,0 \mathrm{~A}$ & $9,0 \mathrm{~A}$ & $0,0 \mathrm{~A}$ & $11,0 \mathrm{~B}$ \\
\hline CV (\%) & 2,94 & 2,42 & 5,93 & 1,91 & 3,27 \\
\hline \multicolumn{6}{|c|}{ Água quente } \\
\hline & Rhizoctonia spp. & Penicillium spp. & Chaetomium spp. & Epicoccum spp. & Outros \\
\hline Testemunha & $83,0 \mathrm{~A}$ & $9,0 \mathrm{~A}$ & $24,0 \mathrm{~A}$ & $20,0 \mathrm{~B}$ & $33,0 \mathrm{~B}$ \\
\hline Água quente a $70^{\circ} \mathrm{C}$ & $20,0 \mathrm{~B}$ & $0,0 \mathrm{~A}$ & $24,0 \mathrm{~A}$ & $64,0 \mathrm{~A}$ & $64,0 \mathrm{~A}$ \\
\hline Água quente a $80^{\circ} \mathrm{C}$ & $25,0 \mathrm{~B}$ & $0,0 \mathrm{~A}$ & $26,0 \mathrm{~A}$ & $0,0 \mathrm{~B}$ & $0,0 \mathrm{C}$ \\
\hline Água quente a $90^{\circ} \mathrm{C}$ & $26,0 \mathrm{~B}$ & $6,0 \mathrm{~A}$ & $24,0 \mathrm{~A}$ & $15,0 \mathrm{~B}$ & $13,0 \mathrm{BC}$ \\
\hline CV (\%) & 2,06 & 2,76 & 2,02 & 4,64 & 5,15 \\
\hline \multicolumn{6}{|c|}{ Imersão em ácido giberélico } \\
\hline & Rhizoctonia spp. & Penicillium spp. & Aspergillus spp. & Outro & \\
\hline Testemunha & $83,0 \mathrm{~A}$ & $88,0 \mathrm{C}$ & $13,0 \mathrm{~A}$ & $33,0 \mathrm{~A}$ & \\
\hline Imersão em $\mathrm{GA}_{3} 250$ por $24 \mathrm{~h}$ & $0,0 \mathrm{~B}$ & $100,0 \mathrm{~A}$ & $30,0 \mathrm{~A}$ & $0,0 \mathrm{~B}$ & \\
\hline Imersão em $\mathrm{GA}_{3} 250$ por $48 \mathrm{~h}$ & $0,0 \mathrm{~B}$ & $82,0 \mathrm{~A}$ & $25,0 \mathrm{~A}$ & $0,0 \mathrm{~B}$ & \\
\hline Imersão em $\mathrm{GA}_{3} 500$ por $24 \mathrm{~h}$ & $0,0 \mathrm{~B}$ & $55,0 \mathrm{~B}$ & $14,0 \mathrm{~A}$ & $3,0 \mathrm{~B}$ & \\
\hline Imersão em $\mathrm{GA}_{3} 500$ por $48 \mathrm{~h}$ & $2,0 \mathrm{~B}$ & $0,0 \mathrm{C}$ & $16,0 \mathrm{~A}$ & $3,0 \mathrm{~B}$ & \\
\hline CV $(\%)$ & 1,83 & 2,54 & 6,22 & 2,34 & \\
\hline \multicolumn{6}{|c|}{ Imersão em $\mathrm{KNO}_{3}$} \\
\hline & \multicolumn{2}{|c|}{ Rhizopus spp. $\quad P$} & icillium spp. & \multicolumn{2}{|c|}{ Outros } \\
\hline Testemunha & \multicolumn{2}{|l|}{$11,0 \mathrm{~A}$} & $9,0 \mathrm{~A}$ & \multicolumn{2}{|c|}{$44,0 \mathrm{~A}$} \\
\hline Imersão em $\mathrm{KNO}_{3}$ por $24 \mathrm{~h}$ & \multicolumn{2}{|l|}{$22,0 \mathrm{~A}$} & $4,0 \mathrm{~A}$ & \multicolumn{2}{|c|}{$21,0 \mathrm{~B}$} \\
\hline Imersão em $\mathrm{KNO}_{3}$ por $48 \mathrm{~h}$ & \multicolumn{2}{|l|}{$20,0 \mathrm{~A}$} & $0,0 \mathrm{~A}$ & \multicolumn{2}{|c|}{$0,0 \mathrm{C}$} \\
\hline CV $(\%)$ & \multicolumn{2}{|l|}{6,00} & 2,99 & \multicolumn{2}{|c|}{3,26} \\
\hline
\end{tabular}

Médias seguidas pela mesma letra na coluna não diferem estatisticamente entre si pelo teste Tukey ao nível de 5\% de probabilidade.

de milho, além de terem sua incidência maximizada com o período de armazenamento, podem causar redução no percentual de germinação.

Verificou-se que a imersão de sementes de aroeira em $\mathrm{GA}_{3} 250$ por 24 horas resultou na incidência de $100 \%$ de Penicillium spp. e a imersão em $\mathrm{GA}_{3} 500$ por 48 horas inibiu o desenvolvimento do fungo. Logo, pode-se concluir que a utilização $\mathrm{GA}_{3}$ na concentração $250 \mathrm{mg} . \mathrm{L}^{-1}$ alterou o $\mathrm{pH}$ da superfície da semente favorecendo o desenvolvimento de Penicillium spp. Segundo Lucca-Filho (1995), os danos causados pelo gênero de fungo Penicillium spp. são variáveis, como: perda de germinação, descoloração das sementes, aumento da taxa de ácidos graxos, aquecimento da massa de sementes e produção de toxinas.

Quando se avaliou a incidência de Rhizoctonia spp. observou-se que os diferentes tempos e concentrações de imersão em $\mathrm{GA}_{3}$ reduziram a incidência de Rhizoctonia spp. para valores próximos a zero. O mesmo pode ser verificado para os fungos classificados como "outros" que também foram reduzidos para valores 
próximos de zero. Resende et al (2008) destacam que alguns fungos, dentre eles Rhizoctonia spp., são os grandes responsáveis pelo tombamento de mudas em viveiros. Estes apresentam estruturas de reprodução ou de sobrevivência que lhes possibilitam habitar o solo por longos períodos de tempo.

Quando se utilizou imersão em $\mathrm{KNO}_{3}$ verificou-se que, para Rhizopus spp. e Penicillium spp. não ocorreu diferença estatística nos diferentes tempos de imersão. $\mathrm{O}$ aumento do tempo de imersão em $\mathrm{KNO}_{3}$ reduz a incidência dos fungos classificados como outros.

Ao realizar análise de correlação entre sementes mortas do teste de germinação e de Rhizopus spp. presente no teste de sanidade, verificou-se correlação positiva e significativa quando se utilizou escarificação ácida e água quente $(\mathrm{r}=0,005$ e $\mathrm{r}=0,00088$, respectivamente). Penicillium spp. é considerado fungo de armazenamento e causador de deterioração das sementes, para este, a correlação foi positiva e significativa quanto se utilizou água quente e ácido giberélico ( $\mathrm{r}=0,05$ e $\mathrm{r}=0,007$, respectivamente). Esse resultado mostrou que os fungos interferem na germinação das sementes de aroeira-preta. Segundo Duarte et al. (2008), estes estão associados à deterioração das sementes e sua ação é dependente das condições físicas e fisiológicas das mesmas, por ocasião da armazenagem, e dos fatores ambientais predominantes no decorrer desse período.

Verificou-se correlação positiva e significativa entre sementes mortas do teste de germinação e Alternaria spp., assim como, para os fungos classificados como outros quando se utilizou o método escarificação ácida $(r=0,02$ e $r=0,03)$. Verzignassi et al. (1997) verificaram que Alternaria steviae e Alternaria alternata estavam associados às sementes de estévia (Stevia rebaudiana), interna e externamente, e foram capazes de causar danos às plântulas, como manchas necróticas na radícula e na parte aérea.

\section{CONCLUSÃO}

Os métodos de superação da dormência escarificação ácida por 20 minutos, imersão em água quente a $70^{\circ} \mathrm{C}, \mathrm{GA}_{3} 250 \mathrm{mg} . \mathrm{L}^{-1}$ por 48 horas e $\mathrm{KNO}_{3}$ por 48 horas podem acelerar o processo de germinação.

Verificou-se a presença dos fungos: Rhizoctonia spp., Penicillium spp., Aspergillus spp.,
Alternaria spp., Chaetomium spp., Epicoccum spp., Rhizopus spp., Phoma spp., Cladosporium spp., Fusarium spp., Trichoderma spp. e Mucor spp., associados às sementes de Lithraea molleoides.

\section{REFERÊNCIAS BIBLIOGRÁFICAS}

BARNETT, H. L.; HUNTER, B. B. Illustred genera of imperfect fungi. 3rd ed. Minnesota: Burgess Publishing Company, 1999. $241 \mathrm{p}$.

BRASIL. Ministério da Agricultura, Pecuária e Abastecimento. Regra para análise de sementes. Brasília, DF, 2009. 399 p.

VAN DER BURG, W. J. et al. Predicting tomato seedling morphology by $\times$-ray analysis of seeds.

Journal American Society for Horticultural Science, v. 119, n. 2, p. 258-263, 1994.

CARVALHO, P. E. R. Espécies arbóreas brasileiras. Brasília: Embrapa Informações Tecnológica; Colombo, PR: Embrapa florestas. 2003. v. 1, p. 727-734.

CARVALHO, P. E. R. Espécies arbóreas brasileiras. Brasília: Embrapa Informações Tecnológica; Colombo, Embrapa florestas, 2006. v. 2, p. 97-104. CHRISTENSEN, C. M. Loss of viability in storage microflora. Seed Science andTechnology. Zurich, v. 1, n. 3, p. 547$562,1973$.

CALON, S. P. Q. et al. Armazenamento, germinação de sementes e crescimento inicial de mudas de Enterolobium contortisiliquum (Vell.) Morong. Acta Scientiarum, v. 27, n. 2, p. 107-112, 2005.

COPELAND, L. O. Principles of seed science and technology. Minnesota: Burgess Publ., 1976. 369 p.DUARTE, L. M. L. et al. Fungos associados às sementes de ipê-amarelo (Tabebuia serratifolia) e ipê-roxo (Tabebuia impetiginosa): incidência, efeito na germinação e transmissão para as plântulas. Summa Phytopathologica. Botucatu, v. 34, n. 4, p. 343-348. out./dez., 2008.

EIRA, M. T. S. Comparação de métodos de quebra de dormência em sementes de capim Andropogon. Revista Brasileira de Sementes. Brasília: v. 5, n. 3, p. 37-49, 1983.

FRANK, L. B.; NABINGER, C. Avaliação da germinação de seis acessos de Paspalum notatum Flügge, nativos do Rio Grande do Sul. Revista Brasileira de Sementes, Brasília, v. 18, n. 1, p. 102-107, 1996.

GARBER, S. D. et al. Theatments affecting 
dormancy in sweet sorghum seed. Seed Science and Technology. Zurich, v. 2, p. 305-316, 1974. GAZZIERO, D. L. P. et al. Estudo da superação de dormência de sementes de capim massambará (Sorghumhalepense(L.)PERS.) através de nitrato de potássio e ácido sulfúrico. Revista Brasileira de Sementes. Brasília: v. 13, n. 1, p. 2125, 1991.

LAURA, V. A.; ALVARENGA, A. A. de; ARIGONI, M. de F. Effects of growth regulators, temperature, light, storage and others factors on Muntingia calabura L. seed germination. Seed Science and Technology. New Delhi, v. 22, n. 3, p. 573-579, 1994. LUCCA-FILHO, O. A. Curso de tecnologia de sementes. Brasília: ABEAS, 1995. 53 p.

LULA, A. A. et al. Estudos de agentes químicos na quebra da dormência de sementes de PaspalumpaniculatumL. Ciência Agrotecnologia, Lavras, v. 24, n. 2, p.358 - 366, abr./jun., 2000.

MARCOS FILHO, J. ; KOMATSU, Y. H.; BARZAGHI, L. Métodos para superar a dormência de sementes de girassol (HelianthusannusL.). Revista Brasileira de Sementes, Brasília, n. 2, p. 65-75, 1987.

MARTINS, C. C.; CARVALHO, N. M.; OLIVEIRA, A. P. Quebra de dormência de sementes de sabiá (Mimosa caesalpiniaefoliaBenth.). Revista Brasileira de Sementes, Pelotas, v. 14, n. 1, p. 5-8, abr., 1992.

MELO, J. T. et al. Coleta, propagação e desenvolvimento inicial de espécies do cerrado. In: SANO, S. M.; ALMEIDA, S. P. (Ed.). Cerrado: ambiente e flora. Planaltina: EMBRAPA/CPAC, 1998. p. 195-235.

MENTEN, J. O. M. Patógenos em sementes: detecção, danos e controle químico. Piracicaba: ESALQ: FEALQ, 1991. 312 p.

MURDOCH,A. J.;ELLIS, R. H. Dormancy, viability and longevity. In: FENNER, M. (Ed.). Seeds: the ecology of regeneration in plant communities. $2^{\text {nd }}$ ed. Wallingford: CABI Publishing, 2000. p.183-214.

MUNIZ, M. F. B. et al. Microflora associadaas sementes de Schinusterebinthifolius Raddi oriundas de frutos em três diferentes estágios de coloração.

Informativo ABRATES, Pelotas, v. 13, n. 3, ago. 2003.

NAKAGAWA, J. Testes de vigor baseados na avaliação de plântulas. In: KRZYZANOWSKI, F. C.; VIEIRA, R. D.; FRANÇA-NETO, J. B. (Ed.). Vigor de sementes: conceitos e testes. Londrina: ABRATES, 1999. p. 1- 2.
NOBRE, S. A. M. et al. Qualidade sanitária e fisiológica de sementes de Myracrodruonurundeuva submetidas ao controle biológico com Clonostachysrosea. In: CONGRESSO BRASILEIRO DE FITOPATOLOGIA, 40., 2007, Maringa-PR. Anais... Maringa-PR , p. 50 , 2007.

OLIVEIRA, J.A. et al. Comportamento de sementes de milho tratadas com fungicidas antes e após o armazenamento convencional. Revista Brasileira de Sementes, Brasília, v. 19, n. 2, p. 208-213, 1997. PIÑA-RODRIGUES, F. C. M.; AGUIAR, I. B. Maturação e dispersão de sementes. In: AGUIAR, I. B.; PIÑA-RODRIGUES, F. C. M.; FIGLIOLIA, M. B. (Org.). Sementes florestais tropicais. Brasília: ABRATES, 1993. p.83-135.

PINTO, N. F. J. A. Patologia de sementes de sorgo. Sete Lagoas: EMBRAPA-CNPMS. 1999. 62 p. (Circular Técnico, 32).

RESENDE, M. L. V.; PÁDUA, M. A.; TOYOTA, M. Manejo das doenças associadas a viveiros florestais. In: DAVIDE, A. C.; SILVA, E. A. A. (Eds). Produção de sementes e mudas de espécies florestais. Lavras: Ed. UFLA, 2008. p. 141-153.

SANTOS, A. F. dos; PARISI, J. J. D. Estado $\mathrm{da}$ arte e perspectivas da patologia de sementes florestais no Brasil. In: SIMPÓSIO BRASILEIRO DE PATOLOGIA DE SEMENTES, 8., 2004, João Pessoa. Anais... João Pessoa, p. 4347, 2004.

SCALON, S. P. Q. et al. Armazenamento, germinação de sementes e crescimento inicial de mudas de Enterolobium contortisiliquum (Vell.) Morong. Acta Scientiarum, v. 27, n. 2, p. 107-112, 2005.

STENZEL, N. M. C.; MURATA, I. M.; NEVES, C. S. V. J. Superação da dormência de sementes de atemóia e fruta-do-conde. Revista Brasileira de Fruticultura, Jaboticabal - SP, v. 25, n. 2, p. 305308, agosto 2003.

TAIZ, L. ZEIGER, E. FisiologiaVegetal. 4. edição, Porto Alegre: Artmed. 2009, 848 p.

VARELA, V. P.; BROCKI, E.; SÁ, S. T. V. Tratamentos pré-germinativos de espécies da amazônia. IV. Faveiracamuzê - Stryphnodendro npulcherrimum(Willd.) Hochr. - Leguminosae. Brasileira de Sementes, Pelotas, v. 13, n. 2, p. 8789, dez., 1991.

VERZIGNASSI, J. R.; VIDA, J. B.; HOMECHIN, M. Ocorrência e transmissão de Alternaria steviaee $A$. alternataem sementes de Steviarebaudiana(Bert.) Bertoni. Revista Brasileira de Sementes, Pelotas, v. 19, n. 2, p. 283 - 287, dez., 1997. 
ZONTA, E. P.; MACHADO, A. A. Sistema de SANEST. Pelotas: UFPEL, 1984. Registro SEI N, análise estatística para microcomputador - 066060-0, Categoria AO. 